\section{BMJ Open Respiratory Research}

\title{
Evaluation of CPAP mask performance during 3 years of mask usage: time for reconsideration of renewal policies?
}

\author{
Atte Laaka (D) , ${ }^{1}$ Maria Hollmén, ${ }^{2,1}$ Adel Bachour ${ }^{1}$
}

To cite: Laaka A, Hollmén M, Bachour A. Evaluation of CPAP mask performance during 3 years of mask usage: time for reconsideration of renewal policies?. BMJ Open Resp Res 2021;8:e001104. doi:10.1136/ bmjresp-2021-001104

- Additional supplemental material is published online only. To view, please visit the journal online (http://dx.doi. org/10.1136/bmjresp-2021001104).

Received 11 September 2021 Accepted 2 November 2021

\section{ABSTRACT}

Background Continuous positive airway pressure (CPAP) mask renewal policies vary inside and between countries. There are no independent studies on the optimal mask renewal frequency. We aimed to evaluate CPAP mask function over time in a real-life clinical setting, and to compare the results against current renewal policies. Methods Daily performance data of 1846 CPAP masks (65\% nasal, $22 \%$ nasal pillows, $12 \%$ oronasal) were recorded from 450 participants (68\% male, mean age 59 years) with obstructive sleep apnoea. The unintentional leak, Apnoea-Hypopnoea Index (CPAP-AHI) and usage data were exported from the CPAP device.

Results Of 656324 nights of CPAP usage, the mean renewal time was 497 days (SD 327), mean leak $5.7 \mathrm{~L} /$ min (SD 8.1) and CPAP-AHI 3.8 events/h (SD 3.6). The difference in mean leak between one $(5.2 \mathrm{~L} / \mathrm{min}, \mathrm{SD} 7.5)$, 12 (6.0 L/min, SD 10.2) and 24 months (5.8L/min, SD 7.5) was minimal $(p=0.59)$. Mean CPAP-AHI remained normal and unchanged in nasal masks and pillows up to 30 months, and was highest in oronasal masks. Different mask manufacturers performed similarly. Masks' daily or total usage did not affect the results. Shifting the mask renewal policy to 24 months could reduce the maskrelated cost up to $50 \%-88 \%$.

Conclusions Nasal masks and pillows could be used at least 2 years without significant changes in unintentional leak and CPAP-AHI. We suggest updating the mask renewal policies of nasal masks and pillows; results on oronasal masks and other manufacturers CPAP devices need further verification.

\section{INTRODUCTION}

Obstructive sleep apnoea (OSA) is the most common sleep-related breathing disorder with an estimated prevalence of $2 \%-7 \%$ worldwide. ${ }^{12}$ It is widely underdiagnosed, and the prevalence is increasing. ${ }^{3-6}$ Untreated OSA causes daytime sleepiness, reduces patient's quality of life, impairs cognitive function and is a risk factor for hypertension and cardiovascular disease. ${ }^{27}$ The diagnosis and severity of OSA is assessed with the Apnoea-Hypopnoea Index (AHI); AHI less than five events/hour is considered normal.

Continuous positive airway pressure (CPAP) therapy is the best available treatment

\section{Key messages}

For how long a continuous positive airway pressure (CPAP) mask could be used without a significant alteration of the functional and therapeutic properties?

Mask renewal policy is mainly regulated by the producer company and differs between the countries and insurance companies. There are no independent institutional studies to assess the validity of this regulation.

- We demonstrated that the CPAP masks remained fit for at least 2 years of use. Hence, the mask renewal policy could be far modified with potential economic benefits.

for moderate (AHI 15-29) to severe OSA $(\mathrm{AHI}>30)$, and with CPAP treatment the AHI should be normalised. ${ }^{8-12}$ CPAP treatment may be administered with a nasal mask, nasal pillows or an oronasal mask. A nasal mask is the preferred and the most commonly used mask type. ${ }^{713-15}$ A proper mask fit is crucial: unintentional leak, that is, air leak around the mask or through the mouth, significantly impairs CPAP function and is one of the most common causes of side effects in CPAP treatment. It additionally brings on nasal congestion, oral dryness and reduces CPAP adherence. ${ }^{716-18}$ CPAP devices can measure and compensate mask leaks. The measuring algorithms are manufacturer-dependent; for devices used in this study (Resmed), the maximum level of acceptable leak is 24L/ min. ${ }^{19}$ However, even smaller leaks can cause significant side-effects, for example, a minor leak blowing to the eye. ${ }^{20}$ Mask fit, patientrelated factors and changes in mask features (silicon parts, strap) can lead to inferior fit.

The optimal mask renewal time is not known. To our knowledge, there are no studies evaluating mask function in continuous use, and mask manufacturers do not provide information on how long the masks function properly. The mask renewal practice varies greatly inside and between countries: in the USA, the majority of states and Medicare 
allow mask renewal after 3 months of use ${ }^{21}$; in the UK, The National Institute for Health and Care Excellence guidelines for the CPAP treatment of OSA suggest a lifespan of 6-12 months. ${ }^{22}$ At our centre, with a patient pool of $1.7 \mathrm{M}$ (approx. $30 \%$ of the population of Finland), we provide one free mask per year for more than 18500 people. Short mask renewal intervals inflict remarkable costs and significant plastic waste. The estimated mean cost of a one CPAP mask is $£ 80$ in the $\mathrm{UK}^{8}$ and between $£ 82$ and $£ 158$ in the USA, depending on mask type and state. ${ }^{21}$ Our total mask-related cost has been approximately $£ 1.8$ $\mathrm{M}$ annually. Due to the growing prevalence and awareness of OSA, this cost is constantly increasing. In the current economic downturn and amidst climate change, it is important to re-evaluate all practice. In the treatment of OSA, determining the optimal mask renewal interval has significant financial and environmental impact.

The purpose of this study is to evaluate: (1) Unintentional air leak (leak) and CPAP-AHI over time in a real-life clinical setting and (2) The annual costs of CPAP masks and the economic impact of prolonging mask renewal.

\section{PATIENTS AND METHODS}

\section{Study design}

The sleep unit provides CPAP devices and masks for patients with OSA free of charge. Devices are replaced every 5 years, and patients are provided one free mask (total mask package) per year on request; more if necessary. Three different types of masks are used: nasal, nasal pillows and oronasal. Due to public procurement regulations, the hospital obtains the CPAP devices and masks through inviting tenders. Neither the hospital nor our group have any direct collaboration with the manufacturers. Hence, our CPAP devices come from one manufacturer, Resmed, and masks from three different manufacturers: Resmed, Philips Respironics, and Fisher \& Paykel. According to the current agreement, the first provided mask is a Resmed mask. Thereafter, the masks are chosen according to patients' preferences and clinical characteristics. None of our study patients used chin straps.

\section{Data sources}

We collected data from 450 consecutive patients who came to replace their Resmed CPAP device after 5 years of use in February 2018. In total, we analysed 658784 nights of CPAP use for 1846 individual masks. Three patients $(0.2 \%)$ were excluded as they had multiple masks at home, and it was impossible to know which of the masks was actually used. When mask usage was less than $15 \mathrm{~min}$, or more than 17 hours, it was accompanied with leak and CPAP-AHI values suggesting the mask had not been worn at all, or the patient forgot to switch off the machine after use. Hence, the 2460 nights $(0.4 \%)$ with less than $15 \mathrm{~min}$ or more than 17 hours of use were excluded from the analyses. In total, this study comprises data of 656324 nights of CPAP use (more than $4.5 \mathrm{M}$ hours), 1843 masks and 450 patients.

The data were collected from the patients' charts and the ResScan programme. We recorded the type, producer, and model for each mask in addition to the patients' age and gender. Mask leak, CPAP-AHI, and usage were recorded for each night of CPAP use. From the daily data, we calculated each masks' mean leak, CPAP-AHI, daily usage, cumulative usage, the number of days since receiving the mask including and excluding days not in use, the number of days between cessation and mask replacement, and the percentage of days the mask was used. We calculated these values for every 1 and 365 days of use, for every 10 and 1000 hours of use, and for each mask in total. In addition, we calculated each mask's mean leak, CPAP-AHI, and daily usage for every week, month and 6 months of use, and for the first and the last 6 months and 1000 hours of use.

\section{Statistical analyses}

We tested all variables for distribution and equality of variances before analyses. Effects of heteroscedasticity were eliminated by using Welch's test for unequal variances as independent t-test and analysis of variance (ANOVA). In case of violation of its assumptions, Mann-Whitney $U$ and Kruskal-Wallis tests were used. When comparing the same mask in different time points, the parametric tests were RM-ANOVA and Paired samples t-test, and, if assumptions were not met, then a Friedman test or Wilcoxon signed-rank test were used. Post hoc group comparisons were analysed with Bonferroni correction, and proportions with $\chi^{2}$-test. As a correlation coefficient, Pearson was used for parametric and Spearmann for non-parametric data. A $p<0.05$ was considered significant. Missing values, and groups with sample size less than ten, were excluded from analyses. We used SPSS V.25.0 for data analysis, and VBA V.7.1. to process output files of ResScan suitable for statistical analyses.

\section{RESULTS}

\section{Patient and mask characteristics}

The patient characteristics are shown in table 1 . Mean age was 59 years, and $68 \%(305 / 145)$ of the patients were male. Female participants were on average 1.8 years older $(\mathrm{p}<0.01)$ and used nasal masks $(\mathrm{p}<0.01)$ more often compared with male.

Nasal masks comprised $65 \%$ of the masks, $22 \%$ were nasal pillows and 12\% oronasal masks. Users of nasal pillows were younger (57.4years, SD 10.5) compared with users of nasal masks (59.2years, SD 10.2; $\mathrm{p}=0.01$ ) and users of oronasal masks (60.4 years, SD 11.6; $\mathrm{p}<0.01$ ). On $76 \%$ of mask renewals, the new model was exactly the same as the old. On $12 \%$ of renewals the mask type was changed. Resmed was the most common manufacturer in all of the mask types. The proportion of mask producers differed between mask types $(p<0.01)$. The shares, mask 
Table 1 Study population and its' characteristics in total and by gender

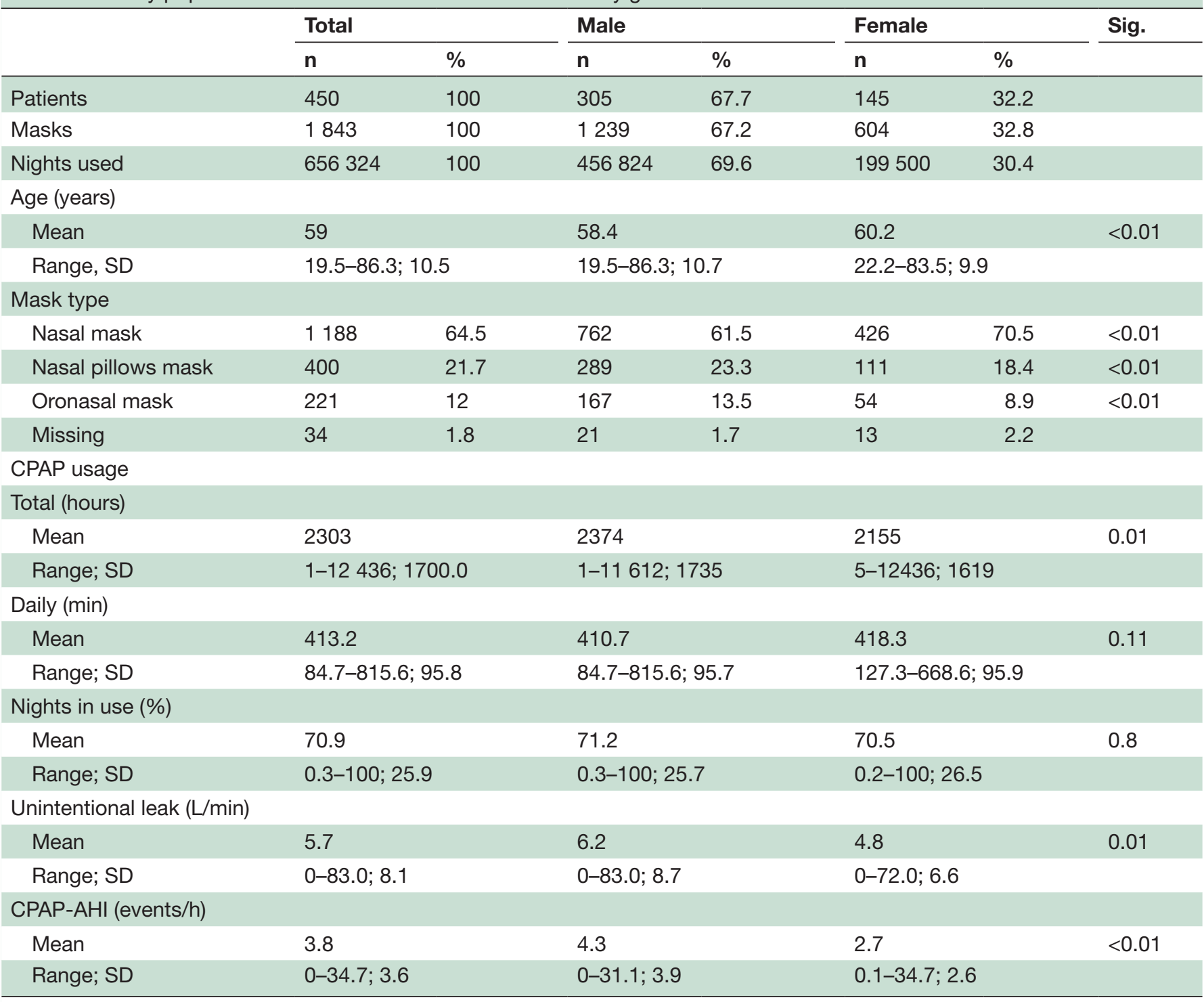

AHI, Apnoea-Hypopnoea Index; CPAP, continuous positive airway pressure.

producers and mask models used in this study are shown in online supplemental table S1.

\section{Mask usage}

The patients renewed their masks on average after 497 days (SD 327 days). They used the masks for a mean 330 (SD 229) days, that is, the masks were used on $71 \%$ of days. The mean total mask usage was 2303 hours (SD 1700 ) and mean daily mask usage 6.9 hours (SD 1.6). Of the 1843 masks, $1182(64 \%)$ were still in use after 1 year, $337(18 \%)$ after 2 years and $154(8 \%)$ after 3 years. Total usage was $>1000$ hours in 1438 masks $(78 \%)$, $>3000$ hours in 455 masks $(25 \%)$ and $>5000$ hours in 137 masks $(7 \%)$. Men replaced their masks later compared with women ( 514 vs 462 days; $p<0.01$ ), but we found no difference in daily mask usage or the percentage of days masks were used.
Oronasal masks were used less (280 days, SD 224 and 1862 hours, SD 1613) compared with nasal masks (335 days, SD 229; $\mathrm{p}<0.01 \& 2363$ hours, SD 1698; $\mathrm{p}<0.01$ ) and nasal pillows (349 days, SD 229; $\mathrm{p}<0.01$ and 2401 hours, SD 1697; $\mathrm{p}<0.01)$. Oronasal masks were used on fewer days $(66.7 \%$, SD 29.8$)$ with shorter daily usage $(6.6$ hour, SD 1.8) compared with nasal masks $(71.9 \%, \mathrm{SD} 25.2 ; \mathrm{p}=0.04$ and 7.0 hour, SD 1.6; $<<0.01)$. The differences in use compared with nasal pillows were not statistically significant $(70.2 \%$, SD 25.7 and 6.8 hours, SD 1.4). Resmed masks were used less often (69.2\%, SD 26.1) compared with Philips Respironics (82.6\%, SD 20.8; p<0.01) and Fisher \& Paykel (75.7\%, SD 26.1; p=0.02) masks. Daily usage was longest with Philips Respironics masks (7.3 hours, SD 1.7) compared with Resmed (6.9 hours, SD 1.6; $\mathrm{p}=0.01$ ) and Fisher \& Paykel (6.5 hours, SD 1.6; $\mathrm{p}<0.01)$. We found no differences in the time the patient 
had the mask, when the patient stopped using the mask, or how many days the mask was used in total.

\section{Leak and CPAP-AHI in the study population}

Mean mask leak was $5.7 \mathrm{~L} / \mathrm{min}$ (SD 8.1) and mean CPAP-AHI 3.8 events/hour (SD 3.6). Both mean leak and CPAP-AHI were higher in men $(6.2 \mathrm{~L} / \mathrm{min}$ and 4.3 events/hour) compared with women $(4.8 \mathrm{~L} / \mathrm{min} ; \mathrm{p}=0.01$ and 2.7 events/hour; $\mathrm{p}<0.01)$. Mean leak was higher in oronasal masks $(6.9 \mathrm{~L} / \mathrm{min}, \mathrm{SD} 11.5 ; \mathrm{p}<0.01)$ and nasal masks $(5.8 \mathrm{~L} / \mathrm{min}, \mathrm{SD} 7.3 ; \mathrm{p}=0.04)$ compared with nasal pillows $(4.7 \mathrm{~L} / \mathrm{min}, \mathrm{SD} 7.0)$. Oronasal masks had higher mean CPAP-AHI (5.1 events/h, SD 5.1) than nasal masks (3.6 events/hour, SD 3.4; $\mathrm{p}<0.01)$ and nasal pillows $(3.7$ events/hour, SD 3.2; $\mathrm{p}=0.04)$. Mean leak and CPAP-AHI were lower in Resmed masks $(5.3 \mathrm{~L} / \mathrm{min}$, SD 7.7 and 3.5 events/hour, SD 3.4) compared with Philips Respironics (6.9L/min, SD 6.1; $\mathrm{p}<0.01$ and 5.6 events/hour, SD 4.1; $\mathrm{p}<0.01)$ and Fisher \& Paykel $(8.4 \mathrm{~L} / \mathrm{min}$, SD 9.9; $\mathrm{p}<0.01$ and 5.0 events/hour, SD 4.9; $\mathrm{p}<0.01)$ masks.

\section{Changes in leak and CPAP-AHI by mask usage}

Mask leak did not correlate with daily usage $(r=0.007$, $\mathrm{p}=0.77$ ). Mean leak and CPAP-AHI did not change significantly during the study period of 30 months of use in relation to the generally accepted levels $24 \mathrm{~L} / \mathrm{min}$ and five events/hour (figure 1).

Mean leak was $5.2 \mathrm{~L} / \mathrm{min}$ (SD 7.5) in the first month, $5.6 \mathrm{~L} / \mathrm{min}(\mathrm{SD} 8.3$ ) at 12 months, and $6.4 \mathrm{~L} / \mathrm{min}$ (SD $8.7)$ at 24 months. When masks were compared with their own performance of 1 month intervals of mask use, the mean change in leak was $+0.8 \mathrm{~L} / \mathrm{min}$ after 12 months and $+0.6 \mathrm{~L} / \mathrm{min}$ after 24 months of use $(\mathrm{p}=0.59)$. The increase in leak became significant after 26 months of use with mean leak $6.9 \mathrm{~L} / \mathrm{min}$ (SD 8.3; $\mathrm{p}<0.01)$. The results remained similar with 6 -month intervals: significant increase was found between 24 and 30 months of use $(p<0.01)$. The mean difference in leak between the first and last 6 months of use, regardless of mask age, was $+0.4 \mathrm{~L} / \mathrm{min}(5.5 \mathrm{~L} / \mathrm{min}$, SD 7.5 and $5.9 \mathrm{~L} / \mathrm{min}$, SD $8.3 ; \mathrm{p}<0.01)$. With cumulative mask usage, significant increase in mean leak was found between 3000 and 4000 hours of use $(p<0.01)$. The mean difference between the first and last 1000 hours of use was $+0.7 \mathrm{~L} / \mathrm{min}(5.5 \mathrm{~L} /$ min, SD 7.8 and $6.2 \mathrm{~L} / \mathrm{min}, \mathrm{SD} 9.0 ; \mathrm{p}<0.01)$.

Nasal masks had a slight increasing trend in leak over time, which was not seen in nasal pillows or oronasal masks (figure 1). When masks were compared with their own performance, the mean difference in leak from one to 24 months was: $+1.2 \mathrm{~L} / \mathrm{min}$ for nasal masks (from $5.6 \mathrm{~L} / \mathrm{min}, \mathrm{p}=0.64$ ),$-0.5 \mathrm{~L} / \mathrm{min}$ for nasal pillows (from

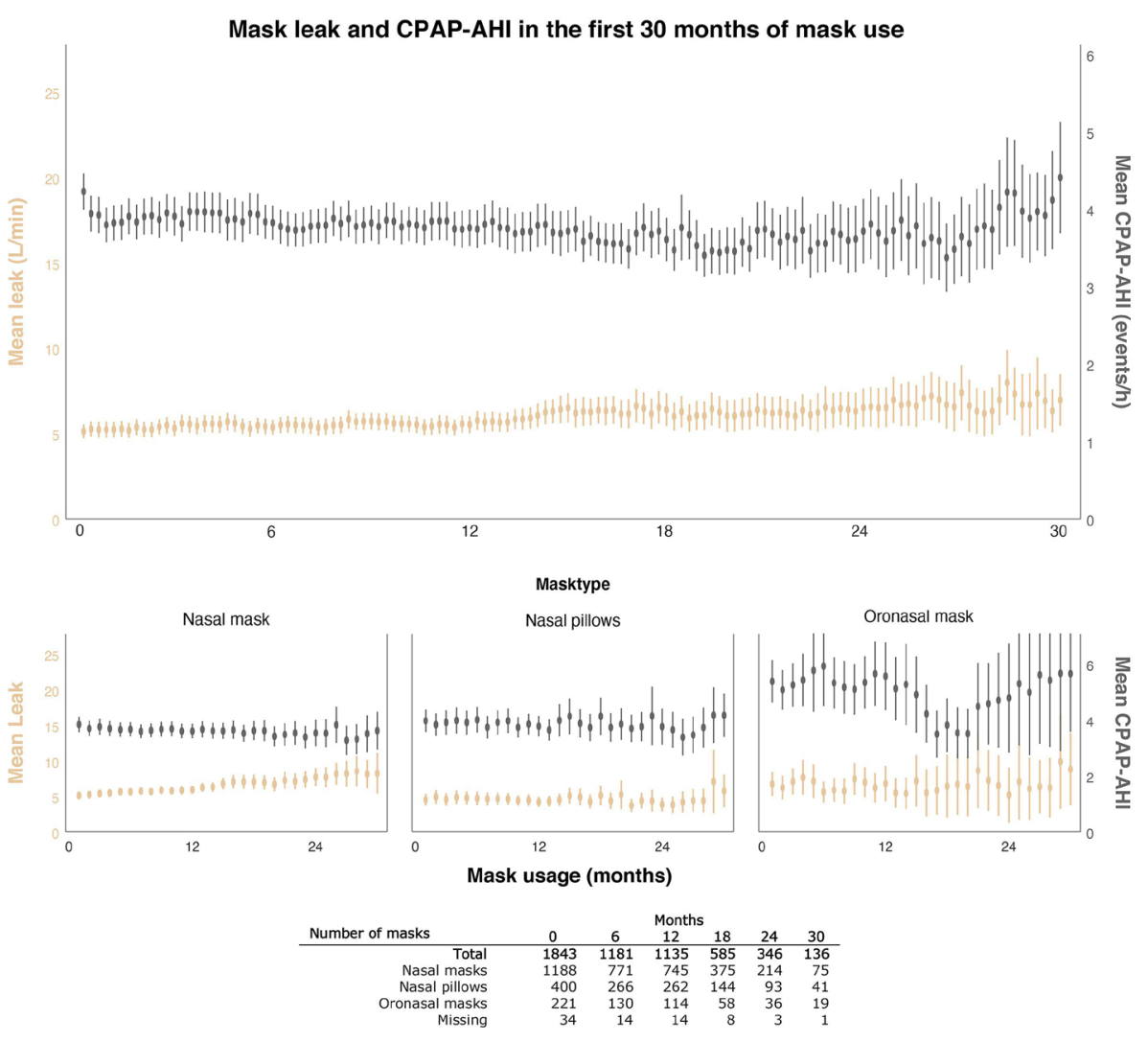

Figure 1 The therapeutic (CPAP-AHI) and functional (leak) measures in CPAP treatment remain unchanged and clinically irrelevant up to 30 months of mask usage. The nasal masks and pillows performed similarly, although a minimal increasing trend is visible in nasal masks. CPAP-AHI is noticeably highest in oronasal masks, regardless of a smaller sample. All error bars represent $95 \% \mathrm{Cl}$. AHI, Apnoea-Hypopnoea Index; CPAP, continuous positive airway pressure. 
3.7 $\mathrm{L} / \mathrm{min}, \mathrm{p}=0.80$ ), and $+0.6 \mathrm{~L} / \mathrm{min}$ for full face masks (from $6.7 \mathrm{~L} / \mathrm{min} ; \mathrm{p}=0.53$ ). Significant change in leak was seen after 26 months of use in nasal masks $(+2.1 \mathrm{~L} / \mathrm{min}$; $\mathrm{p}=0.01$ ). In nasal pillows and oronasal masks, no significant change was found. The increase in leak became significant after 3000 hours in nasal masks $(6.7 \mathrm{~L} / \mathrm{min}$ compared with $5.8 \mathrm{~L} / \mathrm{min} ; \mathrm{p}=0.01$ ) and after 5000 hours of use in nasal pillows $(5.1 \mathrm{~L} / \mathrm{min}$ compared with $3.8 \mathrm{~L} /$ min; $p<0.01)$. We found no significant increase in mask leak up to 26 months (1-month intervals) or 30 months (6-month intervals) in any of the mask manufacturers (data not shown). Mean leak increased after 4000 hours of cumulative usage: $+1.0 \mathrm{~L} / \mathrm{min}$ in Resmed (from $5.1 \mathrm{~L}$ / min, SD 6.2; $\mathrm{p}=0.03),+1.8 \mathrm{~L} / \mathrm{min}$ in Philips Respironics (from $6.0 \mathrm{~L} / \mathrm{min}$, SD 5.8; $\mathrm{p}=0.40$ ), and $+1.6 \mathrm{~L} / \mathrm{min}$ in Fisher \& Paykel (from $8.9 \mathrm{~L} / \mathrm{min}, \mathrm{SD} 7.3 ; \mathrm{p}=0.88$ ).

CPAP-AHI did not correlate with daily usage $(r=-0.004$; $\mathrm{p}=0.86$ ). We found no significant trends regarding CPAP-AHI over time (figure 1). When masks were compared with their own performance, CPAP-AHI was 0.3 events/hour lower during the last 6 months of use compared with the first 6 months (3.6 events/hour, SD 3.4 and 3.9 events/hour, SD $3.8 \& ; \mathrm{p}<0.01)$. Between the first and last 1000 hours of use, the difference was -0.1 events/hour (3.8 events/hour, SD 3.7 and 3.7 events/ hour, SD 3.7; $\mathrm{p}<0.01)$. CPAP-AHI seemed to be noticeably higher in the first week of mask use than in the following months (figure 1). When masks were compared with their own performance, the first month of use differed significantly from the other months $($ all $\mathrm{p}<0.01)$. With 6-month intervals, the only significant difference was found between the first 6 months $(4.5$ events/hours, SD 3.6) and $6-12$ months (4.2 events/hour, SD 3.3; $\mathrm{p}=0.04$ ). In all mask types and mask manufacturers, the differences in CPAP-AHI remained non-significant up to 30 months and 5000 hours of use (data not shown).

\section{Effects of mask renewal intervals on mask-related cost}

An average cost of a CPAP mask is between $£ 80$ and $£ 160 .{ }^{821}$ To minimise overestimation, we use the lowest estimate of $£ 80$ in the calculations. In a theoretical population of 10000 OSA patients, the annual mask related cost is at least $£ 800000$ with a mask renewal interval of 12 months (figure 2 ). The respective annual cost is around $£ 3.2 \mathrm{M}$, if the mask renewal interval is 3 months, and £0.4 $\mathrm{M}$, if it is 24 months. Prolonging mask change intervals up to 24 months reduces the annual mask related cost up to $50 \%-88 \%$, depending on current change intervals.

\section{DISCUSSION}

This study shows that CPAP masks maintain their properties and functionality well in use, and the currently recommended mask renewal intervals could, at the very least, be doubled. To our knowledge, there are no studies on mask endurance in real life, or on optimal mask renewal intervals. The mask manufacturers do not readily provide information on mask resistance to wear and tear.

We found that the therapeutic indicator (CPAP-AHI) remained normal and virtually unchanged for at least 2.5 years and unintentional leak for at least 2 years when nasal masks or nasal pillows were used. Differences between nasal masks and pillows were modest and clinically insignificant, as seen in other studies published recently. ${ }^{14}$ Oronasal masks, conversely, had highest mean leak and CPAP-AHI, in concordance with previous studies. ${ }^{14} 2425$ The increase in leak became visible after 18 months, and patients used them less compared with other mask types.

\section{Estimated annual CPAP mask-related costs for 10000 CPAP users} with different mask renewal policies

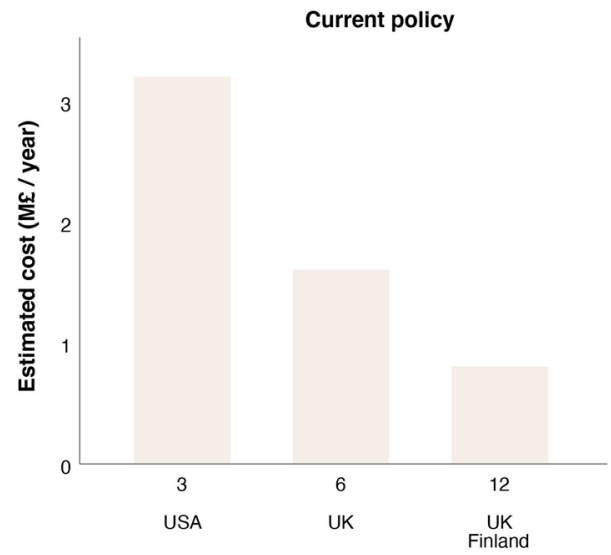

Proposed policy

Mask renewal interval (months)

Figure 2 Estimated mask-related costs with different mask renewal policies. The annual costs could, at least, be halved in all of the three countries by updating the mask renewal policy to 24 months. The current renewal policies vary from 3 to 12 months within and between countries; only the most common intervals are presented. The estimation is calculated for 10 000 CPAP users with a mask price of $£ 80$; the mean mask prices vary from $£ 80$ to $£ 160$ between countries. CPAP, continuous positive airway pressure. 
Patient adherence is a widely recognised problem in CPAP therapy, especially with oronasal masks. ${ }^{15}$ Oronasal masks also require higher CPAP pressures, leading to higher unintentional leaks. ${ }^{25}$ The proportion of men in the oronasal mask group was greater; leak tends to be more common in men, which may be explained by aspects such as facial features, beards and moustaches. Oronasal masks have more contact surface with skin and are thus predisposed to encounter more skin excretions than other mask types, causing more wear and tear, which can explain the weaker performance.

Our results suggest against a substantial deterioration of mask fit over usage or time, especially on nasal masks and pillows, as the masks' function remained similar irrespective of mask use. Cumulative or daily mask usage did not change mean leak or CPAP-AHI compared with just having the mask at home unused. If routine renewal intervals are prolonged, patients should be encouraged to contact the sleep unit if any disturbing air leak appears, and healthcare personnel should pay attention to even small new leaks or other signs of mask deterioration to avoid CPAP interruption. However, mask renewal might not always be the optimal solution; for example, the replacement of individual mask parts has also been associated to better adherence. ${ }^{26}$ Nonetheless, mask renewal might controversially reduce adherence. We have previously shown, that $20 \%$ of patients were unsatisfied with a new mask after renewal, and changing the mask per se multiplies the risk for patient abandoning the whole therapy. ${ }^{27}$ Also in this study, the CPAP-AHI was highest during the first month after renewal, which may be explained by an inferior fit of the new mask. Therefore, short routine mask renewals, or total mask package renewals when the problem only relates to individual mask parts, might impair adherence. Previously, Scharf et al suggested that mask renewal frequency could be used as a surrogate for PAP adherence. In their study, renewing the mask according to the renewal protocol was associated with higher daily CPAP use. However, they do not report the $\mathrm{N}$ of patients renewing their mask more than once and daily CPAP use was rather low. Also, as the authors discuss, the study population (military veterans) does not represent the usual OSA patients and the overall adherence was poor. ${ }^{28}$

The differences between mask brands were modest, and none of the manufacturers performed clearly better than the others. Between all manufacturers, the changes in leak and CPAP-AHI over time were evenly small and statistically nonsignificant. Resmed masks had slightly lower mean leak and CPAP-AHI compared with other brands all-over the study period. Philips Respironics masks were used significantly more compared with Resmed and Fisher \& Paykel masks, and Resmed masks the least. These results may be affected by patient preference or comfort. ${ }^{20}$ In addition, users of other Resmed masks might have gone through more mask model changes to find the optimal mask, as all patients have started with a Resmed mask at the initiation of CPAP treatment. Hence, there might be a confounding factor, if less motivated patients have stopped the treatment/stayed with Resmed masks in comparison to only the most perseverant ones to continue to other brands. Also, as the measuring algorithms are brand-dependable, ${ }^{19}$ the measures on device manufacturers own masks might give more accurate results.

As shown, the mask renewal policies and mask-related costs differ significantly between countries. Short renewal intervals lead to higher costs and bring about significant amounts of non-recyclable plastic waste: at our sleep unit the cost of CPAP masks is approximately $£ 1.8 \mathrm{M}$ annually, and not replacing the masks every year inflicts remarkable savings. The total economic benefit of updating the policy is difficult to evaluate and needs further analysis. As mentioned above, changes in compliance can appear, partly decreasing potential benefits. Compared with mask renewal, an economically valuable solution could be to replace individual mask parts. Meanwhile, it may need more contact with the patient that implies more medical personnel costs.

\section{Strengths and limitations of the study}

This is the first study analysing how long CPAP masks maintain their functionality in a real-life setting. We collected a large data set systematically from a patient pool equaling approximately $30 \%$ of the Finnish population. An average participant in the study represents well the average OSA patient regarding gender, age, mask use and type, and is in line with studies in general. ${ }^{6829}$ Hence, we consider the results applicable to clinical practice in similar populations such as those in Western Europe and the US. Objective data were drawn from the CPAP device, and the follow-up time was several years, while the new remote controlled CPAP devices limit data storage for 12 months. CPAP devices from only one manufacturer were used, reducing bias as the device-recorded measures are brand-dependable. The study included the most commonly used mask types from three leading manufacturers. We do not have any collaboration with the manufacturers. Due to the public healthcare system, neither the cost of the mask nor the patients' insurance affect the choice of mask or renewal time. We evaluated the effect of time, taking into account both the age of the mask and the actual cumulative usage. The number of masks was greater than the number of patients, and we compared the same masks' performance over time, largely reducing effects from confounding factors.

This study also has some limitations. This is a single centre retrospective observational study. The patients' opinions and preferences regarding the masks were not available. We did not have data on several factors that affect mask leak such as nasal congestion, body and head position, nocturnal sweating, coughing, facial hair and maintenance of masks. Due to the strict national tending system the majority of masks, and all of the CPAP devices, were produced by one manufacturer; the findings should be redemonstrated for other manufacturers. All patients were provided total mask packages, so the replacement of individual mask parts could not be evaluated. The majority of the study patients have used the CPAP device for several years; our results may not apply to the first 
year(s) of therapy. Due to the public healthcare system in Finland, our recommendations may have to be modified to fit the needs of other healthcare systems.

\section{CONCLUSIONS}

Based on this study, nasal masks and nasal pillows may be used for at least 2-2.5years without a clinically significant increases in mask leak or CPAP-AHI, whereas oronasal masks need to be renewed annually. The results can be applied to practice, and we have already changed our renewal policy accordingly. Shifting mask renewal policies may reduce the CPAP mask-induced cost significantly, by up to $50 \%-88 \%$, which is an important step in accommodating medical resources to fulfil the increasing challenge of sleep apnoea. However, further prospective studies on mask use and function, and patients' attitudes are needed in the future, especially regarding oronasal masks and the possible effects of CPAP device and mask brands.

Contributors $\mathrm{AL}$ and $\mathrm{MH}$ were responsible of data analysis, visualisation and writing up. $A B$ designed the study, participated incthe data analysis and the writing up and is responsible for the overall content as guarantor. The corresponding author attests that all listed authors meet authorship criteria and that no others meeting the criteria have been omitted.

Funding This study has been supported by The Helsinki University Hospital Research Funds (Y2019SK003).

Competing interests None declared.

Patient consent for publication Not applicable.

Ethics approval This study was performed at the Helsinki University Central Hospital, Heart and Lung Centre, division of Pulmonology, Sleep Unit. The study protocol was approved by the Helsinki University Hospital Ethics Committee, and the Heart and Lung centre (HUS/46/2018, §2, 3 January 2018).

Provenance and peer review Not commissioned; externally peer reviewed. Data availability statement No data are available.

Supplemental material This content has been supplied by the author(s). It has not been vetted by BMJ Publishing Group Limited (BMJ) and may not have been peer-reviewed. Any opinions or recommendations discussed are solely those of the author(s) and are not endorsed by BMJ. BMJ disclaims all liability and responsibility arising from any reliance placed on the content. Where the content includes any translated material, BMJ does not warrant the accuracy and reliability of the translations (including but not limited to local regulations, clinical guidelines, terminology, drug names and drug dosages), and is not responsible for any error and/or omissions arising from translation and adaptation or otherwise.

Open access This is an open access article distributed in accordance with the Creative Commons Attribution Non Commercial (CC BY-NC 4.0) license, which permits others to distribute, remix, adapt, build upon this work non-commercially, and license their derivative works on different terms, provided the original work is properly cited, appropriate credit is given, any changes made indicated, and the use is non-commercial. See: http://creativecommons.org/licenses/by-nc/4.0/.

ORCID iD

Atte Laaka http://orcid.org/0000-0001-5071-6443

\section{REFERENCES}

1 Punjabi NM. The epidemiology of adult obstructive sleep apnea. Proc Am Thorac Soc 2008:5:136-43.

2 Jennum P, Riha RL. Epidemiology of sleep apnoea/hypopnoea syndrome and sleep-disordered breathing. Eur Respir J 2009;33:907-14.

3 Young T, Palta M, Dempsey J, et al. The occurrence of sleepdisordered breathing among middle-aged adults. N Engl J Med 1993;328:1230-5.

4 Lechner M, Breeze CE, Ohayon MM, et al. Snoring and breathing pauses during sleep: interview survey of a United Kingdom population sample reveals a significant increase in the rates of sleep apnoea and obesity over the last 20 years - data from the UK sleep survey. Sleep Med 2019;54:250-6.

5 Steier J, Martin A, Harris J, et al. Predicted relative prevalence estimates for obstructive sleep apnoea and the associated healthcare provision across the UK. Thorax 2014;69:390-2.

6 Peppard PE, Young T, Barnet JH, et al. Increased prevalence of sleep-disordered breathing in adults. Am J Epidemiol 2013;177:1006-14.

7 Gay P, Weaver T, Loube D, et al. Evaluation of positive airway pressure treatment for sleep related breathing disorders in adults. Sleep 2006;29:381-401.

8 McDaid C, Griffin S, Weatherly H, et al. Continuous positive airway pressure devices for the treatment of obstructive sleep apnoeahypopnoea syndrome: a systematic review and economic analysis. Health Technol Assess 2009;13:1.

9 McDaid C, Durée KH, Griffin SC, et al. A systematic review of continuous positive airway pressure for obstructive sleep apnoeahypopnoea syndrome. Sleep Med Rev 2009;13:427-36.

10 Patel SR, White DP, Malhotra A, et al. Continuous positive airway pressure therapy for treating sleepiness in a diverse population with obstructive sleep apnea: results of a meta-analysis. Arch Intern Med 2003;163:565-71.

11 Giles TL, Lasserson TJ, Smith BJ. Continuous positive airways pressure for obstructive sleep apnoea in adults. Cochrane Database Syst Rev 2006:CD001106.

12 Epstein LJ, Kristo D, Strollo PJ, et al. Clinical guideline for the evaluation, management and long-term care of obstructive sleep apnea in adults. J Clin Sleep Med 2009;5:263-76.

13 Chai CL, Pathinathan A, Smith B. Continuous positive airway pressure delivery interfaces for obstructive sleep apnoea. Cochrane Database Syst Rev 2006;4:24.

14 Lebret M, Martinot J-B, Arnol N, et al. Factors contributing to unintentional leak during CPAP treatment: a systematic review. Chest 2017:151:707-19.

15 Borel JC, Tamisier R, Dias-Domingos S, et al. Type of mask may impact on continuous positive airway pressure adherence in apneic patients. PLoS One 2013;8:8.

16 Pépin JL, Leger P, Veale D, et al. Side effects of nasal continuous positive airway pressure in sleep apnea syndrome. study of 193 patients in two French sleep centers. Chest 1995;107:375-81.

17 Bachour A, Maasilta P. Mouth breathing compromises adherence to nasal continuous positive airway pressure therapy. Chest 2004;126:1248-54

18 Valentin A, Subramanian S, Quan SF, et al. Air leak is associated with poor adherence to autoPAP therapy. Sleep 2011;34:801-6.

19 Schwab RJ, Badr SM, Epstein LJ, et al. An official American thoracic Society statement: continuous positive airway pressure adherence tracking systems. The optimal monitoring strategies and outcome measures in adults. Am J Respir Crit Care Med 2013;188:613-20.

20 Bachour A, Vitikainen P, Virkkula P, et al. CPAP interface: satisfaction and side effects. Sleep Breath 2013;17:667-72.

21 Levinson D. Replacement schedules for Medicare continuous positive airway pressure supplies. Department of Health and Human Services, 2013.

22 National Institute for Health and Care Excellence. Continuous positive airway pressure for the treatment of obstructive sleep apnoea/hypopnoea syndrome. (technology appraisal guidance TA139.), 2018. Available: www.nice.org.uk/guidance/ta139/

23 Blanco M, Ernst G, Salvado A, et al. Impact of mask type on the effectiveness of and adherence to unattended home-based CPAP titration. Sleep Disord 2019;2019:1-7.

24 Rowland S, Aiyappan V, Hennessy C, et al. Comparing the efficacy, mask leak, patient adherence, and patient preference of three different CPAP interfaces to treat Moderate-Severe obstructive sleep apnea. J Clin Sleep Med 2018;14:101-8.

25 Deshpande S, Joosten S, Turton A, et al. Oronasal masks require a higher pressure than nasal and nasal pillow masks for the treatment of obstructive sleep apnea. J Clin Sleep Med 2016;12:1263-8.

26 Patel N, Sam A, Valentin A, et al. Refill rates of accessories for positive airway pressure therapy as a surrogate measure of longterm adherence. J Clin Sleep Med 2012;8:169-75.

27 Bachour A, Vitikainen P, Maasilta P. Rates of initial acceptance of Pap masks and outcomes of mask switching. Sleep Breath 2016;20:733-8.

28 Scharf MT, Keenan BT, Pack Al, et al. Mask Refills as a measure of Pap adherence. J Clin Sleep Med 2017;13:1337-44.

29 Sterling KL, Woodford C, Malik A. Epidemiology of patients with obstructive sleep apnea in the United States. American Journal of Respiratory and Critical Care Medicine 2020;201:2. 